\title{
Validating the Quality of Prenatal Care Questionnaire (QPCQ-P) in an Iranian Sample of Pregnant Mothers: A Methodological Study
}

\author{
Mohammad Ali Zakeri \\ Rafsanjan University of Medical Sciences \\ Somaye Khoram \\ Rafsanjan University of Medical Sciences \\ Gholamreza Bazmandegan \\ Rafsanjan University of Medical Sciences \\ Najmeh Ramezani \\ Rafsanjan University of Medical Sciences \\ Batol Talebi \\ Rafsanjan University of Medical Sciences \\ Mahlagha Dehghan ( $\nabla$ m_dehghan86@yahoo.com) \\ Kerman University of Medical Sciences
}

\section{Research Article}

Keywords: Quality of Prenatal Care, QPCQ-P, pregnant, mother

Posted Date: February 17th, 2022

DOI: https://doi.org/10.21203/rs.3.rs-1312563/v1

License: (c) (i) This work is licensed under a Creative Commons Attribution 4.0 International License. Read Full License 


\section{Abstract}

Background: The quality of prenatal care is preventive health care that improves the health outcomes of women and infants. A comprehensive questionnaire can be used to assess the quality of prenatal care as well as to identify and investigate mother-child health outcomes.

Method: In this cross-sectional study, 329 mothers were selected in Rafsanjan, Iran, from May 2019 to February 2020. The validity and reliability of the Quality of Prenatal Care Questionnaire- Persian (QPCQ-P) were determined using criterion validity, Cronbach's alpha, and test-retest reliability. Internal consistency, test-retest reliability, and cross-validation with the Quality of Life-BREF (WHOQOL-BREF) were calculated.

Results: The internal consistency of the QPCQ-P is good $(a=0.936)$ and the item-rest-correlations are fairly good [ICC of 0.476 and confidence interval (CI): 0.20-0.68]. The WHOQOL-BREF and QPCQ-P scores were found to be positively correlated $(r=0.371, p \leq 0.001)$.

Conclusion: This study demonstrates that the QPCQ-P is a reliable and valid measure for the quality of prenatal care. The QPCQ-P scale can be used to identify appropriate care strategies for pregnant mothers.

\section{Background}

Maternal mortality is a major global concern. It is estimated that about one-third of one million women worldwide die each year due to pregnancy [1]. Studies in Iran have shown that the average maternal mortality rate was 21.28 per 100,000 live births per year, which in rural areas, maternal mortality was more than twice that of urban areas [2]. Findings from another study in Iran showed that the maternal mortality rate in Ardabil province is 20 per 100,000 live births [3]. Universal access to high-quality pregnancy and maternity care is a critical prerequisite for reducing maternal mortality [4]. Prenatal care is a type of preventive health care service that is widely used to improve the health of women and babies [5]. Prenatal care has been shown to improve prenatal outcomes such as mother dissatisfaction, low birth weight, and maternal screening for conditions such as pre-eclampsia or gestational diabetes [6].

Prenatal care has long been thought to improve maternal health and birth outcomes. Prenatal and postpartum care is recognized as the key tool for achieving goals, such as lowering child mortality [7]. In this regard, much emphasize has been placed on the quality of prenatal care, including the adequacy of care, the time to start prenatal care, and the number of visits to improve the health outcomes of women and infants [8]. However, a significant number of women still do not have adequate access to prenatal care. Inadequate prenatal care is also influenced by socioeconomic inequalities, demographic factors, and behavioral risk factors [9]. Access to care, physical factors, and the staff and care providers' characteristics are all part of the care structure. There is evidence that prenatal care quality may be more important than care adequacy [8]. Different methods have been used to assess the content and quality of prenatal care. For example, Beeckman et al., (2011) recently developed a tool for measuring the content and time of pregnancy care (CTP) based on recommendations from national and international guidelines. However, the researchers concluded that the content of prenatal care needed to be further developed for new 
measurements and before larger tests could be conducted [10]. Wong et al., also developed a tool to measure the quality of interpersonal care during pregnancy, but this tool measured only one dimension of care quality [11].

The Quality of Prenatal Care Questionnaire (QPCQ) is a reliable scale for assessing the overall quality of prenatal care as well as the quality of care associated with its subscales. The internal consistency of the total scale and its six sub-scales have been confirmed in the Australian population [12]. The quality of prenatal care can be used to compare the quality conflicts in populations and to determine the relationship between quality of care and the different outcomes of mother and child health.

Information sharing, preliminary guidance, appropriate time, usability, accessibility, and support and respect are the six subscales that determine the quality of prenatal care. This scale can be completed after 36 weeks of pregnancy or during the first 6 weeks after delivery for all women who receive prenatal care [13]. The quality of prenatal care has been translated and psychometrically evaluated in a number of languages. Heaman et al. determined the validity of the quality of prenatal care questionnaire to be 0.96 . (2014). The Cronbach's alpha for the Canadian version of the questionnaire was 0.96 , and the results of the test reliability showed an inter-group correlation coefficient of 0.88 [13]. Sword et al. (2015) obtained a Cronbach's alpha of 0.97 in the French version, with Cronbach's alpha ranging from 0.72 to 0.96 for the six subscales [14] as well as a Cronbach's alpha of 0.97 in the Australian version, with Cronbach's alpha ranging from 0.74 to 0.95 for its six sub-scales [12].

The Prenatal Quality of Care Questionnaire fills a gap in the scientific foundation to assess prenatal care and its benefits, and it reflects the quality of care provided by medical institutions during pregnancy [12]. Although, certain aspects of care structure have been identified as key dimensions of the quality of prenatal care, clinical and interpersonal care processes are also essential because they are involved in reducing the unintended consequences and increasing women's participation in self-care. Results suggest that key factors for planning, conducting, and evaluating prenatal care should be prioritized, and that care and decision-making should be centered on women [8].

More research is needed to recognize, educate, and model prenatal care [15]. The current study aimed to standardize an appropriate tool for measuring prenatal care based on recommendations made to assess the validity and reliability of this questionnaire in different populations [14] and the necessity of using this scale to resolve problems and reduce complications before and after delivery. Given the significance of this issue, it is necessary to assess the quality of prenatal care for mothers and provide appropriate evaluation tools. As a result, the goal of this research was to evaluate the psychometric properties of the "Prenatal Quality of Care Questionnaire" in Iranian mothers.

\section{Material And Methods}

This methodological study was conducted from May 2019 to February 2020. The Prenatal Quality of Care questionnaire was administered to 350 mothers who had recently given birth 2.1. Sampling 


\subsubsection{Sample size}

Face validity had a sample size of 20 individuals, qualitative content validity had a sample size of 13 experts, quantitative content validity had a sample size of 15 experts, and test-retest reliability had a sample size of 50 individuals.

Three hundred fifty questionnaires were distributed during the validity phase. A total of 342 questionnaires were returned, resulting in a response rate of 97.71 percent. Due to confounding information and a large number of missing values, 13 questionnaires were excluded after a review of the 342 questionnaires collected. Finally, 329 samples were subjected to the analysis.

The patients were chosen using the convenience sampling method. Inclusion criteria included being over the age of 18 , being familiar with the Persian language, not having severe mental disorders or dementia, and not having had a pregnancy terminated due to premature rupture of the membranes. Mothers with cognitive disorders, active psychological disorders, and underlying diseases such as chronic hypertension, diabetes mellitus, kidney, heart, lung, blood, and liver diseases, as well as known obstetric and medical problems affecting pregnancy status, pregnancy outcomes, and maternal-neonatal health, were excluded from the study.

\subsection{Translation and adaptation}

The Persian version of the QPCQ was derived from the original English version developed by Wendy Sword and Maureen Heaman for the QPCQ committee at McMaster University in Canada. On the other hand, the forward and backward translations were not repeated in the present study as we were not allowed. After making the necessary arrangements with Mr. Wendy Sword, we obtained permission to use this questionnaire in Iran. Furthermore, the necessary agreement was obtained to proceed with the validation process of this questionnaire in Iran. Wendy Sword delivered us the final 46-question Persian version of the questionnaire.

\subsection{Measures}

\section{Demographic and Clinical Variables}

Mothers were asked for information about their age, occupation, education level, number of children, BMI, number of pregnancies, history of abortion, desire to have children, type of current delivery, and admission history.

\section{Quality of Prenatal Care Questionnaire (QPCQ)}

Heaman et al. created the Quality of Prenatal Care Questionnaire (QPCQ) to assess the quality of prenatal care [13]. The QPCQ is a 46-item self-reported questionnaire for women after 36 weeks of pregnancy or within the first 5 days after delivery. This questionnaire consists of 46 items divided into six subscales. The questions are scored on a 5-point Likert scale, with 1 being strongly disagree and 5 being strongly agree. The subscales are 1) information Sharing, 2) anticipatory Guidance, 3) sufficient Time, 4) 
approachability, 5) aAvailability, and 6) support and respect (Table 1). The scores of questions $8,15,23$, 28 , and 40 are reversed. The scores of the QPCQ (46 questions) are between 1 and $5[12,13,16]$. The total score of the QPCQ is calculated by adding the subscale scores. The higher the score, the better the prenatal care. Heaman et al. confirmed the validity of the Canadian version of the questionnaire with a Cronbach's alpha of 0.96 and an intraclass correlation coefficient of 0.88 . Sword et al. showed Cronbach's alpha of 0.97 in the French version [14] and 0.97 in the Australian version [12].

\section{World Health Organization Quality of Life-BREF (WHOQOL-BREF)}

The World Health Organization developed and used this questionnaire to assess individuals' perceptions of their health and quality of life. This questionnaire contains 26 questions divided into four domains: 1) Physical Health Domain, 2) Psychological Domain, 3) Social Relationship Domain, and 4) Environmental Domain. Each item has a score ranging from 1 to 5 . (not at all, low, medium, high, and extremely high). Reverse scoring is used for questions 3,4 , and 25 . To interpret this scale correctly, the short version's scores must be converted to the long version's scores, and then the quality of life in each domain must be interpreted from zero to 100 . In Iran, Cronbach's alpha coefficient of 0.78 has been reported for this questionnaire [17].

\section{Data collection}

The researcher identified the mothers and collected the required samples in different shifts (morning, afternoon, and evening) by obtaining the necessary permits and referring to the departments of obstetrics and gynecology in two public hospitals. The study included all eligible mothers who had a vaginal delivery or a cesarean section and had a maximum of 5 days since their delivery. Samples were collected from May 2019 to February 2020. The questionnaire was completed as a self-report in the presence of the researcher. Interviews were used instead of the self-report method when mothers were unable to complete the questionnaire or were uneducated. We used phone contacts to gather information from those who took part in the test reliability evaluation for the second time.

\section{Ethics}

This study is the result of a research project approved by the Research Ethics Committee of Rafsanjan University of Medical Sciences (IR.RUMS.REC.1397.148). Initially, the researcher provided information to mothers concerning the purposes of the study, the confidentiality of information collected, and voluntary participation and withdrawal. The mothers completed and signed informed consent forms. The content of the fact sheet was explained to those who were uneducated.

\section{Statistical analyses}

SPSS22 was used for all analyses (SPSS Inc., Chicago, Illinois, United States). The significance level of 0.05 was used in this study.

\section{Validity}




\section{Face validity}

The face validity of the QPCQ-P was done qualitatively. Twenty mothers were asked to complete the QPCQ-P in this section. Then they gave their opinions about the appropriateness, problem, relevance, and ambiguity of the questionnaire questions. The time it would take to respond to the questionnaire was estimated, and the necessary changes were made to the questionnaire based on the feedback.

\section{Content validity}

The QPCQ-P content validity was assessed both qualitatively and quantitatively. To assess qualitative content validity, the QPCQ-P was given to 10 eligible experts (2 PhDs in nursing, 3 masters in midwifery, 2 psychologists, and 3 gynecologists), who were asked to evaluate the questionnaire's quality based on grammar, use of appropriate words, phrases, and scoring, as well as to provide their opinions [18]. The questionnaire was then changed in response to the feedback. To assess the QPCQ-P quantitatively, the CVR and the CVI were used. Fifteen experts were provided with QPCQ-P and asked to assess each item on a three-point scale (1. not necessary, 2. useful, but not necessary, and 3. necessary) [19]. If the number obtained from the Lawshe table is greater than 0.49 , the presence of the phrase with the significance level $(p<0.05)$ is necessary and important in this questionnaire [20]. The CVR is calculated using the formula below: where ne is the number of experts who rated the item as "necessary" and $\mathrm{N}$ is the total number of experts.

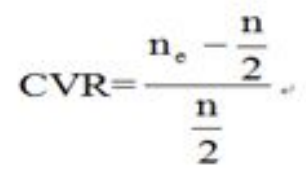

The content validity index (CVI) was used to calculate the three criteria of "simplicity and fluency," "relevance," and "transparency" with a score ranging from 1 (lowest) to 4 (highest) [21]. If an item's score is greater than 0.79 , it will be kept in the questionnaire. If the CVI score falls between 0.79 and 0.70 , the phrase in question should be revised; if it falls below 0.70 , the phrase in question will be unacceptable and should be removed [22]. The CVI formula was as follows:

$\mathrm{CVI}=$ Total number of raters / number of individuals who gave the question score of 3 or 4

\section{Convergent validity}

The correlation between QPCQ-P and WHOQOL-BREF was used to assess convergent validity using the Spearman correlation coefficient. It is assumed that a positive relationship between the QPCQ-P and the WHOQOL-BREF indicates convergent validity ( $<0.30$ low; 0.30 - 0.50: moderate; and $>0.50$ : high) [23].

\section{Reliability}

To assess reliability, the Cronbach's alpha method was used, which is a measure of scale reliability. We considered an alpha of 0.70 or higher to be acceptable $[24,25]$. Using consistency alone to assess 
reliability is frequently insufficient because it provides no information about the consistency of participants' responses (20). As a result, we used test-retest in addition to internal consistency. Cronbach's alpha (0.70) was used to assess internal consistency in our sample, which included 41 mothers. The Internal Correlation Coefficient (ICC) was used to determine the repeatability of QPCQ-P as well as evaluate the reliability of the retest at two-week intervals. To interpret the coefficients, we found values below 0.4 to be unreliable, values between 0.4 and 0.7 to be moderately reliable, and values above 0.7 to be very reliable [22].

\section{Results}

\section{Study Population}

Sample characteristics are summarized in Table 1. The mean age of the participants was $29.06 \pm 5.69$ years (range from 18 to 44 ). The majority of the participants were housewives ( $n=288,87.5 \%$ ), with cesarean delivery $(n=233,70.8 \%)$, and diploma $(n=145,44.1 \%)$. In addition, the QPCQ-P score was $171.97 \pm 21.84$. The QPCQ-P score was significantly associated with age $(P=0.009)$, number of pregnancies $(P=0.02)$, number of deliveries $(P=0.03)$, and QOL $(P<0.001)$.

\section{Description of the QPCQ -P}

The percentage of missing responses, frequency of response options, mean, standard deviation, and median were all used to evaluate the data for each item (Table 2). In general, acceptance of the items was low, with percentages of missing ( $0.3 \%$ for item 2 and item 8$)$. The frequencies of the response categories showed a low use of the category "strongly disagree" (from $0.3 \%$ to $7.6 \%$ ), moderate use of "disagree" (from $0.9 \%$ to $24.9 \%$ ), moderate use of "Neither agree nor disagree" (from $8.2 \%$ to $34.7 \%$ ), high use of the category "agree" (from $29.2 \%$ to $60.8 \%$ ) and the moderate use of the category "strongly agree" (from $9.7 \%$ to $34.7 \%$ ). The mean scores varied from 3.21 (item 23) to 4.10 (item 3). Four items on the scale (items 3 , 5,6 , and 19) have a higher mean score in comparison to the other items in the questionnaire (average higher than four). Standard deviations varied from 0.73 (item 5) to 1.27 (item 15).

\section{Convergent validity}

Table 1 showed that QPCQ-P scores were positively correlated with the quality of life $(Q O L)(r=0.37, P<$ 0.001). As a result of the moderate correlation between QPCQ-P and QOL, convergent validity can be verified with caution.

\section{Reliability}

The Cronbach's alpha of the QPCQ-P was 0.94. The QPCQ-P item-total correlations ranged from 0.028 (Item 23) to 0.69 (Item 19). The item-total correlations were 0.20 or greater for 41 items of the QPCQ-P. Items $8,15,23,28$, and 40 were all less than 0.20 . The test-retest reliability of the QPCQ-P indicated fairly good reliability at a two-week interval with an ICC of 0.48 [confidence interval (CI): 0.20-0.68] (Table 3). Table 4 showed the corrected item-to-total correlation and ICC of the factors of QPCQ-P (the six factors). 
The factor "Support and Respect" had the highest Cronbach's alpha (Cronbach's alpha $=0.86)$ while "Sufficient Time" had the lowest Cronbach's alpha (Cronbach's alpha $=0.63)$.

\section{Discussion}

The present study aimed to investigate the psychometric properties of QPCQ-P in pregnant mothers. The results indicate acceptable psychometric properties of the instrument. The results of this study confirmed the results of the earlier studies on pregnant mothers that suggested the QCPQ could be administered to a woman after 36 weeks of pregnancy and up to 6 weeks postpartum for the quality of prenatal care [12, 13]. Also, the results of the present study are consistent with the psychometric results of this questionnaire by Mohamadi Zeidi et al. [26]. QPCQ reflects the basic elements of good quality prenatal care. Good quality clinical care, communication, education, information, and respect are among these elements [27]. Pregnancy care assessment with QPCQ allows researchers to assess pregnancy time relationships and more accurately measure pregnancy outcomes, health-related behaviors, and use of health services.

\section{Data quality (Floor and ceiling effect)}

The response rate was high, with only two missing data points related to QPCQ-2 and QPCQ-8 of the questionnaire, perhaps because the participants were admitted to the obstetrics and gynecology wards and were thus more accessible due to their admission.

The floor and ceiling effects were evaluated for the items of the QPCQ. The obtained scores are statistically acceptable when less than $15 \%$ of the participants report the lowest or highest possible score [28]. All items had a floor effect of 3.1 percent (ranging from 0.3 to 7.6 percent), and all items had a ceiling effect of 19.24 percent (ranging from 9.7 to 33.7 percent). The floor effect was acceptable (less than $15 \%$ ), but the ceiling effect was not (more than 15\%). A review of the literature in this regard revealed no similar studies, making it impossible to compare these results.

\section{Convergent validity}

The results showed a positive significant correlation between the QPCQ-P and QOL. However, the correlation between QPCQ-P and QOL was moderate. In the French (16) and Australian versions $(r=0.67)$, there was a significant correlation between QPCQ and Patient Expectations and Satisfaction with Prenatal Care (PESPC) $(r=0.85)[12]$.

The QOL questionnaire was used to perform convergent validity in this study because the PESPC version was not validated in Persian, so we had no choice but to use the QOL questionnaire. Since the QPCQ version is similar to the PESPC version, both of which are designed to measure variables in pregnancy, the presence of convergent validity is more likely in the Persian and Australian versions. However, the convergence validity of QPCQ was not strong enough when tested in the Australian population. The reasons for the difference in correlation in the validation test are not entirely clear, but they may be related to differences in the characteristics of the participant. In the Australian version of QPCQ, a higher 
proportion of primiparous women and a lower proportion of married women born in the host country were found as well as less than a high school education [12].

Kassaw et al. showed that the QPCQ was positively correlated with four or more prenatal care visits, higher education of mothers, and household income of more than $175.5 \$$ per month [29]. However, in the present study, variables such as age, number of pregnancies, number of deliveries, and how many births were significantly associated with QPCQ-P. Therefore, the factors affecting pregnancy outcomes and QPCQ should be taken into account when interpreting the findings and should be examined in future studies.

\section{Internal Consistency and Repeatability}

The internal consistency of the QPCQ-P was satisfactory (0.93) and the item-total correlation range was $0.72-0.88$, which is higher than the reported rate of causal study by Mohamadi Zeidi et al (0.0883) [26]. The results of some studies showed that the QPCQ-P was similar to other versions of the QPCQ-P. The Canadian version of QPCQ had a Cronbach's alpha of 0.96 [13]. Cronbach's alpha of the total scale in the French and Australian versions was 0.97 , with subscales ranging from 0.70 to $0.95[12,16]$. In addition, the Cronbach's alpha of the Brazilian-Portuguese version was 0.975 [30].

The intra-class correlation coefficient for QPCQ-P was $0.81(0.72-0.88)$ indicating excellent repeatability $(r \geq 0.75)$ [30]. Reliability coefficients above 0.70 are considered acceptable [31]. Total intra-class correlation coefficients for QPCQ-P are similar to those reported in the Canadian version of QPCQ [e = 0.810 (95\% Cl 0.760-0.850)] [13]. However, the total intra-class correlation coefficient for QPCQ-P is lower than the Brazilian-Portuguese version of the QPCQ [ $r=0.995(95 \% \mathrm{Cl} 0.993-0.996)]$ [30].

\section{Prenatal Care Quality in mothers}

The QPCQ mean score was $3.73 \pm 0.47$ in the present study. The French, Canadian, and Australian versions of the QPCQ had mean scores of $4.41 \pm 0.45$ [16], $4.19 \pm 0.5$ [13], and $4.11 \pm 0.55$, respectively [12]. This difference may indicate that mothers' expectations for prenatal care may decrease their QPCQ scores. In addition, culture can influence QPCQ outcomes, as Kassaw et al. showed that the overall quality of maternal prenatal care was low, and that support of focused prenatal care and infrastructure growth, encouragement of maternal education, and reimbursement of health care costs for low-income women can improve the quality of care [29].

\section{Limitations}

One of the study's strengths is that it provides a useful tool for assessing prenatal quality of care in Iran. However, in order to examine various aspects of this questionnaire in future research, it needs to be reviewed in larger communities. The use of convenience sampling could be one of the limitations of this study. Given the average scores of the subscales, which are relatively high, there is a possibility of a potential selection bias. Women who received high quality care may be more likely to participate in the study than those who received low quality care. In addition, the impact of trained people and maternal caregivers such as midwives can play an effective role in high quality care reporting that should be 
considered. In support of this hypothesis, some studies have shown that having a midwife as a caregiver is the strongest predictor of high quality prenatal care [32]. The QPCQ needs to be tested in a variety of health care systems, service delivery models, and populations that are fundamentally exposed to different social and cultural contexts to demonstrate its validity and reliability in various settings to be used to measure the quality of antenatal care. Furthermore, the validity of this questionnaire was tested within the context of the Iranian health care system, which may yield different results in other care systems. The presence of special conditions in mothers, such as women who are pregnant with complex or high-risk pregnancies, may affect the results of this questionnaire. Another factor to consider is the self-reporting of mothers when completing the QPCQ. Different geographical regions and cultures in Iran also influence our understanding of prenatal quality of care and its proper reporting. Our findings could be supported by the use of a larger and more diverse sample of mothers in various conditions and from various geographical areas in Iran. Finally, to check convergent validity, we did not further conduct sensitivity analysis to provide information on the relative importance of model input parameters and assumptions. Therefore, it is recommended to perform sensitivity analysis in future studies.

\section{Conclusion}

The QPCQ-P appears to be a valid and reliable questionnaire for assessing the quality of prenatal care provided to mothers. The good psychometric properties and strong reliability of the QPCQ-P confirm its use as a useful tool for measuring prenatal care. However, it is necessary to examine this questionnaire in larger groups and across cultures as well as to evaluate its clinical and practical aspects in order to assist managers and researchers in developing and implementing maternal health policies.

\section{Practice implications}

Given that QPCQ is a valid measure of prenatal care in mothers, it can be used to understand the health status of mother and baby, assist mothers in maintaining healthy behaviors, identify concerns about prenatal care, familiarize mothers with problems encountered, help to standardize maternal health care, and coordinate mothers with the health care system. Understanding prenatal care is the first step in examining the relationship between such care and the various outcomes of pregnancy that may affect the health of both mother and baby. On the other hand, it has a direct impact on resource allocation, policy planning and development, and the improvement of maternal pregnancy.

\section{Declarations}

\section{Acknowledgements}

Thanks to the cooperation and support of the Vice Chancellery for Research and Technology (VCRT) of the Rafsanjan University of Medical Sciences (this study is part of the research project No.

IR.RUMS.97260). We would like to thank all the participants who completed the QPCQ-P as well as the support and collaboration of the Clinical Research Development Unit (IR.RUMS.REC.1397.148) in Ali-Ibn Abi-Talib Hospital, Rafsanjan University of Medical Sciences, Rafsanjan, Iran. 


\section{Authors' contributions}

MAZ and MD contributed to the conception and design of the study. SK, NR and BT contributed in data collection. MAZ wrote the frst draft of paper, and all authors commented on subsequent drafts. MAZ and MD analysed the data. MAZ, MD, GB, SK, NR and BT reviewed the article critically and approved the fnal version of manuscript.

\section{Funding}

No external funding.

\section{Availability of data and materials}

The datasets generated and/or analyzed during the current study are not publicly available due to patient privacy but are available from the corresponding author on reasonable request.

\section{Ethics approval and consent to participate}

This study was approved by the "Ethics Committee of Rafsanjan University of Medical Sciences (IR.RUMS.REC.1397.148). All methods were carried out in accordance with relevant guidelines and regulations. Informed consent was obtained from all subjects and/or their legal guardian(s). The participants were ensured of the confidentiality of their information and the right to withdraw from the study.

\section{Consent for publication}

Not applicable.

\section{Competing interests}

The authors declare that they have no competing interests

\section{References}

1. Organization, W.H., Trends in maternal mortality: 1990 to 2008. Estimates developed by WHO, UNICEF, UNFPA and The World Bank. Trends in maternal mortality: 1990 to 2008. Estimates developed by WHO, UNICEF, UNFPA and The World Bank, 2010.

2. Mirahmadizadeh, A., et al., Maternal mortality rate and its causes in the south of Iran. Acta facultatis medicae Naissensis, 2020. 37(2): p. 180-190. DOI: 10.5937/afmnai2002180M.

3. Farzollahpour, F. and R. Imani, Evaluation factors affecting the maternal mortality among pregnant women during 2001-2011 in Ardabil Province, Iran. Medical Research Journal, 2019. 4(2): p. 89-94. DOI: 10.5603/MRJ.a2019.0022.

4. Campbell, O.M., W.J. Graham, and L.M.S.S.s. group, Strategies for reducing maternal mortality: getting on with what works. The lancet, 2006. 368(9543): p. 1284-1299. https://doi.org/10.1016/S0140- 
6736(06)69381-1.

5. Edwards, S.L. and M. Sabato, A Nurse's Survival Guide to Critical Care E-Book. 2009: Elsevier Health Sciences.

6. McFadden, A., et al., Support for healthy breastfeeding mothers with healthy term babies. The Cochrane Library, 2017: p. https://doi.org/10.1002/14651858.CD001141.pub5.

7. Information, U.N.D.o.P., Millennium Development Goals Report 2009 (Includes the 2009 Progress Chart). 2009: United Nations Publications.

8. Sword, W., et al., Women's and care providers' perspectives of quality prenatal care: a qualitative descriptive study. BMC pregnancy and childbirth, 2012. 12(1): p. 29. https://doi.org/10.1186/14712393-12-29.

9. Ribeiro, E.R., et al., Risk factors for inadequate prenatal care use in the metropolitan area of Aracaju, Northeast Brazil. BMC pregnancy and childbirth, 2009. 9(1): p. 31. https://doi.org/10.1186/1471-23939-31.

10. Beeckman, K., et al., The development and application of a new tool to assess the adequacy of the content and timing of antenatal care. BMC health services research, 2011. 11(1): p. 213. https://doi.org/10.1186/1472-6963-11-213.

11. Wong, S.T., C.C. Korenbrot, and A.L. Stewart, Consumer assessment of the quality of interpersonal processes of prenatal care among ethnically diverse low-income women: development of a new measure. Women's Health Issues, 2004. 14(4): p. 118-129. https://doi.org/10.1016/j.whi.2004.04.003.

12. Sword, W., et al., Quality of prenatal care questionnaire: psychometric testing in an Australia population. BMC pregnancy and childbirth, 2015. 15(1): p. 214. https://doi.org/10.1186/s12884-0150644-7.

13. Heaman, M.I., et al., Quality of prenatal care questionnaire: instrument development and testing. BMC pregnancy and childbirth, 2014. 14(1): p. 188. https://doi.org/10.1186/1471-2393-14-188.

14. Wendy Sword PhD, R., R. Maureen Heaman PhD, and R. Ann Salvador MPA, Psychometric Testing of the French Language Quality of Prenatal Care Questionnaire. Journal of nursing measurement, 2015. 23(3): p. 436.

15. Coley, S.L. and R.E. Aronson, Exploring birth outcome disparities and the impact of prenatal care utilization among North Carolina teen mothers. Women's Health Issues, 2013. 23(5): p. e287-e294. https://doi.org/10.1016/j.whi.2013.06.004.

16. Sword, W., et al., Psychometric testing of the French language quality of prenatal care questionnaire. Journal of nursing measurement, 2015. 23(3): p. 436-451. DOI: 10.1891/1061-3749.23.3.436.

17. Zakeri, M.A., et al., Chronic Patients' Activation and Its Association with Stress, Anxiety, Depression, and Quality of Life: A Survey in Southeast Iran. BioMed Research International, 2021. 2021: p. https://doi.org/10.1155/2021/6614566.

18. Colton, D. and R.W. Covert, Designing and constructing instruments for social research and evaluation. 2007: First ed. San Francisco: John Wiley \& Sons. 
19. Cook, D.A. and T.J. Beckman, Current concepts in validity and reliability for psychometric instruments: theory and application. The American journal of medicine, 2006. 119(2): p. 166. e7-166. e16. https://doi.org/10.1016/j.amjmed.2005.10.036.

20. Lawshe, C.H., A quantitative approach to content validity 1. Personnel psychology, 1975. 28(4): p. 563575. https://doi.org/10.1111/j.1744-6570.1975.tb01393.x.

21. Waltz, C.F., O.L. Strickland, and E.R. Lenz, Measurement in nursing and health research. 2010: Springer publishing company.

22. Jay Lynn, S., et al., Mindfulness, acceptance, and hypnosis: Cognitive and clinical perspectives. International Journal of Clinical and Experimental Hypnosis, 2006. 54(2): p. 143-166. https://doi.org/10.1080/00207140500528240.

23. Echevarría-Guanilo, M.E., N. Gonçalves, and P.J. Romanoski, Psychometric properties of measurement instruments: conceptual basis and evaluation methods-Part II. Texto \& Contexto-Enfermagem, 2019. 28: p. https://doi.org/10.1590/1980-265x-tce-2017-0311.

24. Sanchis-Gomar, F., et al., Epidemiology of coronary heart disease and acute coronary syndrome. Annals of translational medicine, 2016. 4(13): p. https://doi.org/10.21037/atm.2016.06.33.

25. Clark, L.A. and D. Watson, Constructing validity: Basic issues in objective scale development. Psychological assessment, 1995. 7(3): p. 309.

26. Mohamadi Zeidi, B., et al., Psychometric Evaluation of Persian Version of Quality of Prenatal Care Questionnaire. International Journal of Pediatrics, 2021. 9(8): p. 14280-14292. http:// ijp.mums.ac.ir.

27. Renfrew, M.J., et al., Midwifery and quality care: findings from a new evidence-informed framework for maternal and newborn care. The Lancet, 2014. 384(9948): p. 1129-1145. http://dx.doi.org/10.1016/S0140-6736(14)60789-3.

28. Ateef, M., Measurement properties of the Knee Injury and Osteoarthritis Outcome Score PatelloFemoral questionnaire in Saudi Arabians. PeerJ, 2020. 8: p. e9323. https://doi.org/10.7717/peerj.9323.

29. Kassaw, A., A. Debie, and D.M. Geberu, Quality of prenatal care and associated factors among pregnant women at public health facilities of Wogera District, Northwest Ethiopia. Journal of pregnancy, 2020. 2020: p. https://doi.org/10.1155/2020/9592124.

30. Nunes, R.D., et al., Cross-cultural adaptation and psychometric properties of the Brazilian-Portuguese version of the Quality of Prenatal Care Questionnaire (QPCQ). Revista de saude publica, 2018. 53: p. 01. https://doi.org/10.11606/S1518-8787.2019053000565.

31. Polit, D.F. and C.T. Beck, Nursing research: Principles and methods. 2004: Lippincott Williams \& Wilkins.

32. Kandasamy, M., Do women's sociodemographic characteristics or type of prenatal care provider influence quality of prenatal care? https://macsphere.mcmaster.ca/bitstream/11375/12942/1/fulltext.pdf. Accessed 10 June 2015. 2013. 


\section{Tables}

Table 1: Demographic and clinical information of the participants $(N=329)$. 


\begin{tabular}{|c|c|c|c|}
\hline \multirow[t]{2}{*}{ Variables } & \multirow[t]{2}{*}{ Mean (SD) } & \multicolumn{2}{|l|}{ QPCQ-P } \\
\hline & & Spearman Correlation Coefficient & $P$ value \\
\hline Age (yr.) & $29.06(5.69)$ & 0.14 & 0.009 \\
\hline Mother's BMI & $29.45(5.63)$ & 0.06 & 0.27 \\
\hline Infant's BMI & $13.35(1.55)$ & -0.02 & 0.67 \\
\hline Number of pregnancies (Gravid) & $2.09(0.96)$ & 0.12 & 0.02 \\
\hline Number of deliveries & $1.85(0.75)$ & 0.12 & 0.03 \\
\hline Number of abortions & $0.24(0.53)$ & 0.06 & 0.24 \\
\hline Number of children & $1.84(0.74)$ & 0.10 & 0.68 \\
\hline \multirow[t]{2}{*}{ Quality of life (QOL) } & $58.06(12.45)$ & 0.37 & $<0.001$ \\
\hline & $N(\%)$ & Statistical test & $P$ value \\
\hline \multicolumn{4}{|l|}{ Type of delivery } \\
\hline Vaginal & $96(29.20)$ & \multirow[t]{2}{*}{$Z=-2.09$} & \multirow[t]{2}{*}{0.04} \\
\hline Cesarean & $233(70.80)$ & & \\
\hline \multicolumn{4}{|l|}{ Infant } \\
\hline Male & $167(50.80)$ & $Z=-0.66$ & 0.50 \\
\hline Female & $162(49.20)$ & & \\
\hline \multicolumn{4}{|l|}{ Type of previous delivery } \\
\hline Vaginal & 78 (23.70) & & \\
\hline Cesarean & $133(40.40)$ & $H=7.59$ & 0.02 \\
\hline No & $118(35.90)$ & & \\
\hline \multicolumn{4}{|l|}{ Occupational status of the mother } \\
\hline Employed & $41(12.50)$ & $Z=-0.15$ & 0.87 \\
\hline Housewife & $288(87.50)$ & & \\
\hline Educational level of mother & & $H=1.24$ & 0.53 \\
\hline < Diploma & $72(21.9)$ & & \\
\hline Diploma & $145(44.1)$ & & \\
\hline Academic & $112(34.0)$ & & \\
\hline Family income level (Million Riyal) & & & \\
\hline
\end{tabular}




\begin{tabular}{|c|c|c|c|}
\hline$<0.5$ & $198(60.2)$ & \multirow[t]{4}{*}{$H=6.64$} & \multirow[t]{4}{*}{0.08} \\
\hline $0.5-1$ & 70 (21.3) & & \\
\hline $1-2$ & $48(14.6)$ & & \\
\hline$>2$ & $13(4.0)$ & & \\
\hline \multicolumn{4}{|c|}{ Other Illnesses } \\
\hline Yes & $162(49.2)$ & \multirow[t]{2}{*}{$Z=-1.46$} & \multirow[t]{2}{*}{0.14} \\
\hline No & $167(50.8)$ & & \\
\hline $\begin{array}{l}\text { Data } \\
\text { Prenat }\end{array}$ & $=$ Mann Wh & U test; $\mathrm{H}=$ & \\
\hline
\end{tabular}

\section{Table 2. Data description of the Persian version of the QPCQ (QPCQ -P)}




\begin{tabular}{|c|c|c|c|c|c|c|c|c|c|}
\hline Questions & $\mathbf{N}$ & $\begin{array}{l}\text { Missing } \\
\text { values }\end{array}$ & $\begin{array}{l}\text { Strongly } \\
\text { disagree }\end{array}$ & Disagree & $\begin{array}{l}\text { Neither } \\
\text { agree } \\
\text { nor } \\
\text { disagree }\end{array}$ & Agree & $\begin{array}{l}\text { Strongly } \\
\text { agree }\end{array}$ & Mean & SD \\
\hline QPCQ 1 & 329 & $0(0.0)$ & $5(1.5)$ & $9(2.7)$ & $\begin{array}{l}50 \\
(15.2)\end{array}$ & $\begin{array}{l}195 \\
(59.3)\end{array}$ & $\begin{array}{l}70 \\
(21.3)\end{array}$ & 3.96 & 0.78 \\
\hline QPCQ 2 & 328 & $1(0.3)$ & $14(4.3)$ & $\begin{array}{l}39 \\
(11.9)\end{array}$ & $\begin{array}{l}74 \\
(22.5)\end{array}$ & $\begin{array}{l}153 \\
(46.5)\end{array}$ & $\begin{array}{l}48 \\
(14.6)\end{array}$ & 3.55 & 1.01 \\
\hline QPCQ 3 & 329 & $0(0.0)$ & $2(0.6)$ & $12(3.6)$ & 27 (8.2) & $\begin{array}{l}196 \\
(59.6)\end{array}$ & $\begin{array}{l}92 \\
(28.0)\end{array}$ & 4.10 & 0.74 \\
\hline QPCQ 4 & 329 & $0(0.0)$ & $4(1.2)$ & $18(5.5)$ & $\begin{array}{l}57 \\
(17.3)\end{array}$ & $\begin{array}{l}168 \\
(51.1)\end{array}$ & $\begin{array}{l}82 \\
(24.9)\end{array}$ & 3.93 & 0.86 \\
\hline QPCQ 5 & 329 & $0(0.0)$ & $2(0.6)$ & $6(1.8)$ & $\begin{array}{l}37 \\
(11.2)\end{array}$ & $\begin{array}{l}181 \\
(55.0)\end{array}$ & $\begin{array}{l}103 \\
(31.3)\end{array}$ & 4.14 & 0.73 \\
\hline QPCQ 6 & 329 & $0(0.0)$ & $1(0.3)$ & $8(2.4)$ & $\begin{array}{l}51 \\
(15.5)\end{array}$ & $\begin{array}{l}169 \\
(51.4)\end{array}$ & $\begin{array}{l}100 \\
(30.4)\end{array}$ & 4.09 & 0.75 \\
\hline QPCQ 7 & 329 & $0(0.0)$ & $6(1.8)$ & $15(4.6)$ & $\begin{array}{l}80 \\
(24.3)\end{array}$ & $\begin{array}{l}164 \\
(49.8)\end{array}$ & $\begin{array}{l}64 \\
(19.5)\end{array}$ & 3.80 & 0.86 \\
\hline QPCQ 8 & 328 & $1(0.3)$ & $19(5.8)$ & $\begin{array}{l}56 \\
(17.0)\end{array}$ & $\begin{array}{l}61 \\
(18.5)\end{array}$ & $\begin{array}{l}125 \\
(38.0)\end{array}$ & $\begin{array}{l}67 \\
(20.4)\end{array}$ & 3.50 & 1.16 \\
\hline QPCQ 9 & 329 & $0(0.0)$ & $12(3.6)$ & $\begin{array}{l}33 \\
(10.0)\end{array}$ & $\begin{array}{l}63 \\
(19.1)\end{array}$ & $\begin{array}{l}166 \\
(50.5)\end{array}$ & $\begin{array}{l}55 \\
(16.7)\end{array}$ & 3.66 & 0.98 \\
\hline QPCQ 10 & 329 & $0(0.0)$ & $5(1.5)$ & $\begin{array}{l}33 \\
(10.0)\end{array}$ & $\begin{array}{l}76 \\
(23.1)\end{array}$ & $\begin{array}{l}154 \\
(46.8)\end{array}$ & $\begin{array}{l}61 \\
(18.5)\end{array}$ & 3.70 & 0.93 \\
\hline QPCQ 11 & 329 & $0(0.0)$ & $9(2.7)$ & $32(9.7)$ & $\begin{array}{l}80 \\
(24.3)\end{array}$ & $\begin{array}{l}160 \\
(48.6)\end{array}$ & $\begin{array}{l}48 \\
(14.6)\end{array}$ & 3.62 & 0.94 \\
\hline QPCQ 12 & 329 & $0(0.0)$ & $22(6.7)$ & $\begin{array}{l}62 \\
(18.8)\end{array}$ & $\begin{array}{l}90 \\
(27.4)\end{array}$ & $\begin{array}{l}119 \\
(36.2)\end{array}$ & $\begin{array}{l}36 \\
(10.9)\end{array}$ & 3.25 & 1.09 \\
\hline QPCQ 13 & 329 & $0(0.0)$ & $9(2.7)$ & $19(5.8)$ & $\begin{array}{l}67 \\
(20.4)\end{array}$ & $\begin{array}{l}179 \\
(54.4)\end{array}$ & $\begin{array}{l}55 \\
(16.7)\end{array}$ & 3.76 & 0.89 \\
\hline QPCQ 14 & 329 & $0(0.0)$ & $8(2.4)$ & $21(6.4)$ & $\begin{array}{l}66 \\
(20.1)\end{array}$ & $\begin{array}{l}178 \\
(54.1)\end{array}$ & $\begin{array}{l}56 \\
(17.0)\end{array}$ & 3.76 & 0.89 \\
\hline QPCQ 15 & 329 & $0(0.0)$ & $21(6.4)$ & $\begin{array}{l}54 \\
(16.4)\end{array}$ & $\begin{array}{l}42 \\
(12.8)\end{array}$ & $\begin{array}{l}98 \\
(29.8)\end{array}$ & $\begin{array}{l}114 \\
(34.7)\end{array}$ & 3.69 & 1.27 \\
\hline QPCQ 16 & 329 & $0(0.0)$ & $9(2.7)$ & $\begin{array}{l}41 \\
(12.5)\end{array}$ & $\begin{array}{l}73 \\
(22.2)\end{array}$ & $\begin{array}{l}148 \\
(45.0)\end{array}$ & $\begin{array}{l}58 \\
(17.6)\end{array}$ & 3.62 & 1.00 \\
\hline QPCQ 17 & 329 & $0(0.0)$ & $9(2.7)$ & $20(6.1)$ & $\begin{array}{l}64 \\
(19.5)\end{array}$ & $\begin{array}{l}162 \\
(49.2)\end{array}$ & $\begin{array}{l}74 \\
(22.5)\end{array}$ & 3.82 & 0.93 \\
\hline QPCQ 18 & 329 & $0(0.0)$ & $4(1.2)$ & $7(2.1)$ & $\begin{array}{l}48 \\
(14.6)\end{array}$ & $\begin{array}{l}200 \\
(60.8)\end{array}$ & $\begin{array}{l}70 \\
(21.3)\end{array}$ & 3.98 & 0.74 \\
\hline
\end{tabular}




\begin{tabular}{|c|c|c|c|c|c|c|c|c|c|}
\hline Questions & $\mathbf{N}$ & $\begin{array}{l}\text { Missing } \\
\text { values }\end{array}$ & $\begin{array}{l}\text { Strongly } \\
\text { disagree }\end{array}$ & Disagree & $\begin{array}{l}\text { Neither } \\
\text { agree } \\
\text { nor } \\
\text { disagree }\end{array}$ & Agree & $\begin{array}{l}\text { Strongly } \\
\text { agree }\end{array}$ & Mean & SD \\
\hline QPCQ 19 & 329 & $0(0.0)$ & $3(0.9)$ & 11 (3.3) & $\begin{array}{l}35 \\
(10.6)\end{array}$ & $\begin{array}{l}191 \\
(58.1)\end{array}$ & $\begin{array}{l}89 \\
(27.1)\end{array}$ & 4.06 & 0.76 \\
\hline QPCQ 20 & 329 & $0(0.0)$ & $5(1.5)$ & $14(4.3)$ & $\begin{array}{l}44 \\
(13.4)\end{array}$ & $\begin{array}{l}184 \\
(55.9)\end{array}$ & $\begin{array}{l}82 \\
(24.9)\end{array}$ & 3.98 & 0.83 \\
\hline QPCQ 21 & 329 & $0(0.0)$ & $8(2.4)$ & $22(6.7)$ & $\begin{array}{l}86 \\
(26.1)\end{array}$ & $\begin{array}{l}167 \\
(50.8)\end{array}$ & $\begin{array}{l}46 \\
(14.0)\end{array}$ & 3.67 & 0.88 \\
\hline QPCQ 22 & 329 & $0(0.0)$ & $10(3.0)$ & $11(3.3)$ & $\begin{array}{l}53 \\
(16.1)\end{array}$ & $\begin{array}{l}186 \\
(56.5)\end{array}$ & $\begin{array}{l}69 \\
(21.0)\end{array}$ & 3.89 & 0.87 \\
\hline QPCQ 23 & 329 & $0(0.0)$ & $21(6.4)$ & $\begin{array}{l}82 \\
(24.9)\end{array}$ & $\begin{array}{l}80 \\
(24.3)\end{array}$ & $\begin{array}{l}96 \\
(29.2)\end{array}$ & $\begin{array}{l}50 \\
(15.2)\end{array}$ & 3.21 & 1.16 \\
\hline QPCQ 24 & 329 & $0(0.0)$ & $18(5.5)$ & $32(9.7)$ & $\begin{array}{l}114 \\
(34.7)\end{array}$ & $\begin{array}{l}131 \\
(39.8)\end{array}$ & $\begin{array}{l}34 \\
(10.3)\end{array}$ & 3.39 & 0.98 \\
\hline QPCQ 25 & 329 & $0(0.0)$ & $7(2.1)$ & $11(3.3)$ & $\begin{array}{l}75 \\
(22.8)\end{array}$ & $\begin{array}{l}181 \\
(55.0)\end{array}$ & $\begin{array}{l}55 \\
(16.7)\end{array}$ & 3.80 & 0.82 \\
\hline QPCQ 26 & 329 & $0(0.0)$ & $4(1.2)$ & $9(2.7)$ & $\begin{array}{l}61 \\
(18.5)\end{array}$ & $\begin{array}{l}185 \\
(56.2)\end{array}$ & $\begin{array}{l}70 \\
(21.3)\end{array}$ & 3.93 & 0.78 \\
\hline QPCQ 27 & 329 & $0(0.0)$ & $18(5.5)$ & $\begin{array}{l}55 \\
(16.7)\end{array}$ & $\begin{array}{l}95 \\
(28.9)\end{array}$ & $\begin{array}{l}129 \\
(39.2)\end{array}$ & $32(9.7)$ & 3.31 & 1.03 \\
\hline QPCQ 28 & 329 & $0(0.0)$ & $8(2.4)$ & $\begin{array}{l}57 \\
(17.3)\end{array}$ & $\begin{array}{l}73 \\
(22.2)\end{array}$ & $\begin{array}{l}116 \\
(35.3)\end{array}$ & $\begin{array}{l}75 \\
(22.8)\end{array}$ & 3.58 & 1.09 \\
\hline QPCQ 29 & 329 & $0(0.0)$ & $22(6.7)$ & $\begin{array}{l}39 \\
(11.9)\end{array}$ & $\begin{array}{l}102 \\
(31.0)\end{array}$ & $\begin{array}{l}130 \\
(39.5)\end{array}$ & $\begin{array}{l}36 \\
(10.9)\end{array}$ & 3.36 & 1.04 \\
\hline QPCQ 30 & 329 & $0(0.0)$ & $10(3.0)$ & $10(3.0)$ & $\begin{array}{l}46 \\
(14.0)\end{array}$ & $\begin{array}{l}198 \\
(60.2)\end{array}$ & $\begin{array}{l}65 \\
(19.8)\end{array}$ & 3.90 & 0.85 \\
\hline QPCQ 31 & 329 & $0(0.0)$ & $25(7.6)$ & $\begin{array}{l}42 \\
(12.8)\end{array}$ & $\begin{array}{l}66 \\
(20.1)\end{array}$ & $\begin{array}{l}136 \\
(41.3)\end{array}$ & $\begin{array}{l}60 \\
(18.2)\end{array}$ & 3.49 & 1.15 \\
\hline QPCQ 32 & 329 & $0(0.0)$ & $11(3.3)$ & $29(8.8)$ & $\begin{array}{l}65 \\
(19.8)\end{array}$ & $\begin{array}{l}171 \\
(52.0)\end{array}$ & $\begin{array}{l}53 \\
(16.1)\end{array}$ & 3.68 & 0.95 \\
\hline QPCQ 33 & 329 & $0(0.0)$ & $3(0.9)$ & $10(3.0)$ & $\begin{array}{l}61 \\
(18.5)\end{array}$ & $\begin{array}{l}192 \\
(58.4)\end{array}$ & $\begin{array}{l}63 \\
(19.1)\end{array}$ & 3.91 & 0.75 \\
\hline QPCQ 34 & 329 & $0(0.0)$ & $15(4.6)$ & $\begin{array}{l}34 \\
(10.3)\end{array}$ & $\begin{array}{l}95 \\
(28.9)\end{array}$ & $\begin{array}{l}153 \\
(46.5)\end{array}$ & 32 (9.7) & 3.46 & 0.96 \\
\hline QPCQ 35 & 329 & $0(0.0)$ & $9(2.7)$ & $21(6.4)$ & $\begin{array}{l}78 \\
(23.7)\end{array}$ & $\begin{array}{l}170 \\
(51.7)\end{array}$ & $\begin{array}{l}51 \\
(15.5)\end{array}$ & 3.70 & 0.90 \\
\hline QPCQ 36 & 329 & $0(0.0)$ & $10(3.0)$ & $19(5.8)$ & $\begin{array}{l}93 \\
(28.3)\end{array}$ & $\begin{array}{l}169 \\
(51.4)\end{array}$ & $\begin{array}{l}38 \\
(11.6)\end{array}$ & 3.62 & 0.87 \\
\hline
\end{tabular}




\begin{tabular}{|c|c|c|c|c|c|c|c|c|c|}
\hline Questions & $\mathbf{N}$ & $\begin{array}{l}\text { Missing } \\
\text { values }\end{array}$ & $\begin{array}{l}\text { Strongly } \\
\text { disagree }\end{array}$ & Disagree & $\begin{array}{l}\text { Neither } \\
\text { agree } \\
\text { nor } \\
\text { disagree }\end{array}$ & Agree & $\begin{array}{l}\text { Strongly } \\
\text { agree }\end{array}$ & Mean & SD \\
\hline QPCQ 37 & 329 & $0(0.0)$ & $3(0.9)$ & $9(2.7)$ & $\begin{array}{l}65 \\
(19.8)\end{array}$ & $\begin{array}{l}179 \\
(54.4)\end{array}$ & $\begin{array}{l}73 \\
(22.2)\end{array}$ & 3.94 & 0.78 \\
\hline QPCQ 38 & 329 & $0(0.0)$ & $17(5.2)$ & $\begin{array}{l}34 \\
(10.3)\end{array}$ & $\begin{array}{l}63 \\
(19.1)\end{array}$ & $\begin{array}{l}161 \\
(48.9)\end{array}$ & $\begin{array}{l}54 \\
(16.4)\end{array}$ & 3.61 & 1.04 \\
\hline QPCQ 39 & 329 & $0(0.0)$ & $10(3.0)$ & $27(8.2)$ & $\begin{array}{l}85 \\
(25.8)\end{array}$ & $\begin{array}{l}164 \\
(49.8)\end{array}$ & $\begin{array}{l}43 \\
(13.1)\end{array}$ & 3.61 & 0.92 \\
\hline QPCQ 40 & 329 & $0(0.0)$ & $7(2.1)$ & $\begin{array}{l}54 \\
(16.4)\end{array}$ & $\begin{array}{l}44 \\
(13.4)\end{array}$ & $\begin{array}{l}113 \\
(34.3)\end{array}$ & $\begin{array}{l}111 \\
(33.7)\end{array}$ & 3.81 & 1.13 \\
\hline QPCQ 41 & 329 & $0(0.0)$ & $10(3.0)$ & $11(3.3)$ & $\begin{array}{l}59 \\
(17.9)\end{array}$ & $\begin{array}{l}184 \\
(55.9)\end{array}$ & $\begin{array}{l}65 \\
(19.8)\end{array}$ & 3.86 & 0.87 \\
\hline QPCQ 42 & 329 & $0(0.0)$ & $25(7.6)$ & $\begin{array}{l}57 \\
(17.3)\end{array}$ & $\begin{array}{l}78 \\
(23.7)\end{array}$ & $\begin{array}{l}132 \\
(40.1)\end{array}$ & $\begin{array}{l}37 \\
(11.2)\end{array}$ & 3.30 & 1.11 \\
\hline QPCQ 43 & 329 & $0(0.0)$ & $7(2.1)$ & $18(5.5)$ & $\begin{array}{l}65 \\
(19.8)\end{array}$ & $\begin{array}{l}180 \\
(54.7)\end{array}$ & $\begin{array}{l}59 \\
(17.9)\end{array}$ & 3.80 & 0.86 \\
\hline QPCQ 44 & 329 & $0(0.0)$ & $7(2.1)$ & $3(0.9)$ & $\begin{array}{l}54 \\
(16.4)\end{array}$ & $\begin{array}{l}198 \\
(60.2)\end{array}$ & $\begin{array}{l}67 \\
(20.4)\end{array}$ & 3.95 & 0.77 \\
\hline QPCQ 45 & 329 & $0(0.0)$ & $10(3.0)$ & $9(2.7)$ & $\begin{array}{l}48 \\
(14.6)\end{array}$ & $\begin{array}{l}183 \\
(55.6)\end{array}$ & $\begin{array}{l}79 \\
(24.0)\end{array}$ & 3.94 & 0.87 \\
\hline QPCQ 46 & 329 & $0(0.0)$ & $7(2.1)$ & $5(1.5)$ & $\begin{array}{l}60 \\
(18.2)\end{array}$ & $\begin{array}{l}185 \\
(56.2)\end{array}$ & $\begin{array}{l}72 \\
(21.9)\end{array}$ & 3.94 & 0.80 \\
\hline
\end{tabular}

Table 3. Corrected item-to-total correlation, Cronbach's alpha and ICC of the QPCQ-P (reliability) 
Corrected Item-

Total Correlation

$(n=329)$
Cronbach's Alpha if Item Deleted ( $\mathrm{n}$

= 329)
ICC

(Cl)

( $\mathrm{n}=$

41)

1. I had as much time with my prenatal care provider(s) as I needed

0.52

0.93

0.77

$(0.61-$

$0.87)$

2. My prenatal care provider(s) gave me options $\quad 0.46$

0.94

0.76

for my birth experience

$(0.59-$

0.86 )

3. I was given adequate information about prenatal tests and procedures

0.58

0.93

0.26

$(-0.28$

$-0.32)$

4. I was given enough information to meet my needs about breastfeeding

0.60

0.93

0.50

$(0.23-$

$0.70)$

5. My prenatal care provider(s) respected me

0.62

0.93

0.38

$(0.08-$

0.61 )

6. I was always given honest answers to my questions

0.61

0.93

0.58

$(0.34-$

$0.75)$

7. My prenatal care provider(s) respected my knowledge and experience

0.54

0.93

0.67

$(0.46-$

$0.81)$

8. My prenatal care provider(s) was rushed

0.07

0.94

0.84

$(0.72-$

$0.91)$

9. I knew how to get in touch with my prenatal care provider(s)

0.47

0.94

0.77

$(0.61-$

$0.87)$

10. My prenatal care provider(s) prepared me for

0.54

0.93

0.67

my birth experience

$(0.47-$

$0.81)$

11. Everyone involved in my prenatal care

0.41

0.94

0.79

received the important information about me

$(0.64-$

$0.88)$

12. Someone in my prenatal care provider(s)'s

0.42

0.94

0.77

office always returned my calls

$(0.62-$

$0.87)$

13. My prenatal care provider(s) spent time talking with me about my expectations for labour

0.68

0.93

0.58

$(0.34-$

$0.75)$ and delivery 
Corrected Item-

$(n=329)$
Total Correlation
Cronbach's Alpha if Item Deleted ( $\mathrm{n}$

= 329)
ICC

(Cl)

$(n=$

41)

14. My decisions were respected by my prenatal $\quad 0.68$

$0.68 \quad 0.93$

0.56

care provider(s)

0.14

0.94

$(0.30-$

$0.73)$

15. My prenatal care provider(s) was abrupt with me

0.22

$(-0.08$

$-0.49)$

16. I was given enough information about the safety of moderate exercise during pregnancy

0.47

0.94

0.57

$(0.32-$

$0.74)$

17. I was screened adequately for potential problems with my pregnancy

0.50

0.93

0.44

$(0.15-$

$0.65)$

18. My prenatal care provider(s) always had time $\quad 0.67$

$0.67 \quad 0.933$

0.41

to answer my questions

$(0.13-$

$0.64)$

19. My prenatal care provider(s) was patient

0.69

0.93

0.15

$(-0.16$

$-0.43)$

20. I received adequate information about my diet during pregnancy

0.64

0.93

0.38

$(0.09-$

$0.61)$

21. I was supported by my prenatal care

0.44

0.94

0.42

provider(s) in doing what I felt was right for me

$(0.13-$

$0.64)$

22. The results of tests were explained to me in a $\quad 0.60$

0.93

$-0.05$

way I could understand

$(-0.35$

$-0.25)$

23. I was rushed during my prenatal care visits

0.03

0.94

0.72

$(0.53-$

$0.84)$

24. My prenatal care provider(s) was interested in $\quad 0.36$

$0.36 \quad 0.94$

0.59

how my pregnancy was affecting my life

$(0.35-$

$0.76)$

25. My prenatal care provider(s) supported me

0.62

0.93

0.18

$(-0.12$

$-0.46)$

26. My prenatal care provider(s) paid close

attention when I was speaking

0.68

0.93

0.39

$(0.10-$

$0.62)$ 


\section{Questions}

Corrected Item-

Total Correlation

$(n=329)$
Cronbach's Alpha if Item Deleted ( $\mathrm{n}$

= 329)
ICC

(Cl)

$(n=$

41)

27. I was linked to programs in the community $\quad 0.55$

$0.55 \quad 0.93$

0.54

that were helpful to me

28. My prenatal care provider(s) made me feel

like I was wasting their time

0.17

0.94

$(0.29-$

$0.73)$

0.54

$(0.29-$

$0.73)$

29. My concerns were taken seriously

0.31

0.94

0.68

$(0.48-$

$0.81)$

30. My prenatal care provider(s) made time for me to talk

0.55

0.93

0.10

$(-0.20$

$-0.39)$

31. I received adequate information about

alcohol use during pregnancy

0.44

0.94

0.55

$(0.29-$

$0.73)$

32. My prenatal care provider(s) was available when I had questions or concerns

0.63

0.93

0.67

$(0.46-$

$0.81)$

33. My prenatal care provider(s) gave

0.65

0.93

0.32

straightforward answers to my questions

$(0.01-$

$0.56)$

34. I was in control of the decisions being made $\quad 0.27$

0.94

0.48

about my prenatal care

$0.21-$

$0.68)$

35. I could always reach someone in the

0.58

0.93

0.55

office/clinic if I needed something

$(0.30-$

$0.73)$

36. My prenatal care provider(s) supported my

0.55

0.934

0.50 decisions

0.68

0.933

$(0.23-$

$0.70)$

37. I was at ease with my prenatal care provider(s)

0.18

$(-0.12$

$-0.46)$

38. I could reach my prenatal care provider(s) by $\quad 0.52$

0.934

0.60

phone when necessary

$(0.36-$

$0.76)$

39. My prenatal care provider(s) gave me enough $\quad 0.52$

0.934

0.42

information to make decisions for myself

$(0.14-$

$0.64)$ 


\begin{tabular}{|c|c|c|c|}
\hline Questions & $\begin{array}{l}\text { Corrected Item- } \\
\text { Total Correlation } \\
(\mathrm{n}=329)\end{array}$ & $\begin{array}{l}\text { Cronbach's Alpha } \\
\text { if Item Deleted ( } \mathrm{n} \\
=329 \text { ) }\end{array}$ & $\begin{array}{l}\text { ICC } \\
(\mathrm{Cl}) \\
(\mathrm{n}= \\
41)\end{array}$ \\
\hline $\begin{array}{l}\text { 40. I was afraid to ask my prenatal care } \\
\text { provider(s) questions }\end{array}$ & 0.16 & 0.937 & $\begin{array}{l}0.25 \\
(-0.05 \\
-0.52)\end{array}$ \\
\hline $\begin{array}{l}\text { 41. My values and beliefs were respected by my } \\
\text { prenatal care provider(s) }\end{array}$ & 0.63 & 0.933 & $\begin{array}{l}0.62 \\
(0.39- \\
0.78)\end{array}$ \\
\hline $\begin{array}{l}\text { 42. I was given adequate information about } \\
\text { depression in pregnancy }\end{array}$ & 0.46 & 0.935 & $\begin{array}{l}0.73 \\
(0.55- \\
0.84)\end{array}$ \\
\hline $\begin{array}{l}\text { 43. My prenatal care provider(s) kept my } \\
\text { information confidential }\end{array}$ & 0.51 & 0.934 & $\begin{array}{l}0.79 \\
(0.64- \\
0.88)\end{array}$ \\
\hline $\begin{array}{l}\text { 44. My prenatal care provider(s) took time to } \\
\text { listen }\end{array}$ & 0.62 & 0.934 & $\begin{array}{l}0.60 \\
(0.36- \\
0.76)\end{array}$ \\
\hline $\begin{array}{l}\text { 45. I fully understood the reasons for blood work } \\
\text { and other tests my prenatal care provider(s) } \\
\text { ordered for me }\end{array}$ & 0.50 & 0.934 & $\begin{array}{l}0.55 \\
(0.29- \\
0.73)\end{array}$ \\
\hline $\begin{array}{l}\text { 46. My prenatal care provider(s) took time to ask } \\
\text { about things that were important to me }\end{array}$ & 0.64 & 0.933 & $\begin{array}{l}0.52 \\
(0.26- \\
0.71)\end{array}$ \\
\hline
\end{tabular}

The QPCQ-P Cronbach's alpha = 0.936; ICC: Interclass correlation; Cl: Confidence interval; QPCQ -P: Quality of Prenatal Care Questionnaire - Persian.

Table 4. Corrected item-to-total correlation and ICC of The Factors of QPCQ-P (reliability) 


\begin{tabular}{|c|c|c|c|c|c|c|}
\hline Questions & Minimum & Maximum & Mean & $S D$ & $\begin{array}{l}\text { Cronbach's } \\
\text { Alpha }\end{array}$ & $\begin{array}{l}\text { ICC (Cl) } \\
(n=41)\end{array}$ \\
\hline $\begin{array}{l}\text { Factor } 1 \text { - } \\
\text { Information Sharing }\end{array}$ & 1.89 & 5.00 & 3.87 & 0.53 & 0.80 & $\begin{array}{l}0.47(0.19- \\
0.68)\end{array}$ \\
\hline $\begin{array}{l}\text { Factor } 2 \text { - } \\
\text { Anticipatory Guidance }\end{array}$ & 1.45 & 5.00 & 3.63 & 0.60 & 0.84 & $\begin{array}{l}0.70(0.51- \\
0.83)\end{array}$ \\
\hline Factor 3 - Sufficient Time & 1.80 & 5.00 & 3.86 & 0.55 & 0.63 & $\begin{array}{l}0.61(0.38- \\
0.77)\end{array}$ \\
\hline Factor 4 - Approachability & 1.00 & 5.00 & 3.57 & 0.84 & 0.69 & $\begin{array}{l}0.56(0.31- \\
0.74)\end{array}$ \\
\hline Factor 5 - Availability & 1.40 & 5.00 & 3.58 & 0.69 & 0.73 & $\begin{array}{l}0.58(0.34- \\
0.75)\end{array}$ \\
\hline $\begin{array}{l}\text { Factor } 6 \text { - } \\
\text { Support and Respect }\end{array}$ & 1.83 & 5.00 & 3.78 & 0.53 & 0.86 & $\begin{array}{l}0.31(0.01- \\
0.56)\end{array}$ \\
\hline Total QPCQ & 1.98 & 5.00 & 3.73 & 0.47 & 0.94 & $\begin{array}{l}0.81(0.72- \\
0.88)\end{array}$ \\
\hline
\end{tabular}

The QPCQ-P Cronbach's alpha = 0.936; ICC: Interclass correlation; Cl: Confidence interval; SD: Standard deviation; QPCQ -P: Quality of Prenatal Care Questionnaire - Persian 